\title{
Butein induces cell apoptosis and inhibition of cyclooxygenase-2 expression in A549 lung cancer cells
}

\author{
YANG LI ${ }^{1}$, CHENGYUAN MA $^{2}$, MING QIAN ${ }^{3}$, ZHONGMEI WEN $^{1}$, HONGYU JING $^{1}$ and DONGHUA QIAN ${ }^{1}$ \\ Departments of ${ }^{1}$ Respiration and ${ }^{2}$ Neurosurgery, The First Hospital of Jilin University; \\ ${ }^{3}$ Department of Prosthodontics, Stomatological Hospital, Jilin University, Changchun, Jilin 130021, P.R. China
}

Received July 18, 2013; Accepted November 29, 2013

DOI: $10.3892 / \mathrm{mmr} .2013 .1850$

\begin{abstract}
Butein is a flavonoid isolated from the bark of Rhus verniciflua Stokes and the flowers of Butea monosperma, and is known to be a potential therapeutic drug for treating inflammation and cancer. Cyclooxygenase (COX) converts arachidonic acid to prostanoids, and increased expression of its isoform, COX-2, has been observed in lung cancer tissue. The aim of the present study was to investigate expression alteration of COX-2 in A549 lung cancer cells following butein treatment at the mRNA and protein levels by quantitative polymerase chain reaction and western blotting, respectively. It was observed that COX-2 mRNA and protein levels were significantly downregulated in the butein treatment group in comparison with the control group $(\mathrm{P}<0.05)$. In addition, the effects of butein on proliferation and apoptosis were evaluated. The data demonstrated that butein induces cell-cycle arrest and apoptosis in human lung cancer cells. These results indicated that butein may be a promising candidate drug for lung cancer treatment.
\end{abstract}

\section{Introduction}

The flavonoid butein may be isolated from the bark of Rhus verniciflua Stokes and the flowers of Butea monosperma. It is a biologically active flavonoid, and a number of studies have reported its anticarcinogenic activities (1-3). The organic extract purified from Rhus verniciflua Stokes inhibits the growth of transformed hepatic cells, but not the untransformed parent cells (4), whereas butein alone may introduce $\mathrm{G}(2) / \mathrm{M}$ phase arrest in hepatic cells (5). Its anti-proliferative or pro-apoptotic effects may be induced through downregulating STAT3-related gene expression (6) and inhibiting telomerase activity (7). The flavonoid may also re-sensitize the tumor

Correspondence to: Professor Donghua Qian, Department of Respiration, The First Hospital of Jilin University, 71 Xinmin Street, Chaoyang, Changchun, Jilin 130021, P.R. China

E-mail: donghuaqian604@163.com

Key words: butein, lung cancer, cyclooxygenase-2, A549 necrosis factor $\alpha$-related apoptosis-inducing ligand (TRAIL) resistant leukemia cells undergoing apoptosis following TRAIL treatment (8), and may reduce clonogenic growth of human breast cancer cells (9). These experiments indicated the potential anticarcinogenic effect of butein on different cell types.

Prostaglandins may be produced from arachidonic acid with the enzyme cyclooxygenase (COX) in tumor tissues. Increased expression of COX-2 in the neovasculature of breast tumors has been observed, which suggests that the enzyme may be involved in the later stage of cancer development. In the estrogen receptor-positive MCF-7 cells, COX-2 overexpression increases the growth rate and colony formation in soft agar, and promotes movement across the Matrigel basement membrane (10). By contrast, overexpressing COX-2 in the Hs578T estrogen receptor-negative breast cancer cell line also activates matrix metalloproteinase-2 (11). These activities may encourage the invasiveness of cancer cells and facilitate metastasis. Altered gene expression in cell cycle and apoptosis, or their regulatory signals may also support tumorigenesis. Notably, COX-2 may increase the expression of the epidermal growth factor receptor, aromatase, and $\mathrm{Bcl}-2$, which may be integrated into these processes (12).

COX-2 inhibitors have shown a degree of protection against breast carcinogenesis in animal models. Celecoxib inhibits the onset and progression of 7,12-dimethylbenz[a] anthracene-induced mammary tumorigenesis in rats, while nimesulide reduces tumor incidence induced by 2-amino-1-me thyl-6-phenylimidazo[4,5-b]pyridine (13). These experimental results have demonstrated that $\mathrm{COX}-2$ inhibition may protect against cancer. Therefore, the inhibition of COX-2 has been suggested to be a promising therapeutic strategy for human cancer, thus, indicating the importance of overcoming the therapeutic resistance of cancer and the possible role of COX-2 in cancer. In the current study, the effect of butein on COX-2 expression in human lung cells was investigated. Furthermore, the effects of butein on proliferation and apoptosis in A549 lung cancer cells were evaluated.

\section{Materials and methods}

Chemicals and drugs. Butein was obtained from Jilin University (Changchun, China), dimethylsulfoxide (DMSO), Tris-HCl, EDTA, SDS, phenylmethylsulfonyl fluoride (PMSF), 
bovine serum albumin (BSA), leupeptin, Nonidet P-40, deoxycholic acid, sodium orthovanadate, aprotinin and a polyclonal antibody against $\beta$-actin were purchased from Sigma-Aldrich (St. Louis, MO, USA). Protein assay kits were obtained from Bio-Rad Laboratories (Hercules, CA, USA). Dulbecco's modified Eagle's medium (DMEM) and fetal-bovine serum (FBS) were obtained from Gibco-Life Technologies (Carlsbad, CA, USA). COX-2 polyclonal antibodies were purchased from Santa Cruz Biotechnology, Inc. (Santa Cruz, CA, USA). Anti-mouse secondary antibodies were purchased from Qiagen (Hilden, Germany).

Cell culture. The A549 non-small cell lung carcinoma (NSCLC) cell line was obtained from the Cell Bank of the Chinese Academy of Sciences (Shanghai, China) and cultured in DMEM supplemented with heat-inactivated FBS (10\%), L-glutamine $(2 \mathrm{mM})$, penicillin $(100 \mathrm{IU} / \mathrm{ml})$, and streptomycin $(100 \mu \mathrm{g} / \mathrm{ml})$ in a humidified incubator aerated with $5 \% \mathrm{CO}_{2}$ and $95 \%$ at $37^{\circ} \mathrm{C}$. When cells reached $70-80 \%$ confluency, they were trypsinized, counted and treated with celastrol in complete cell medium. Control cells were treated with vehicle (DMSO) for the same duration.

Cell viability assay. Cells were plated in 96-well culture plates at an initial density of $1 \times 10^{4}$ cells/well and allowed to adhere to the plates. The culture medium was replaced by fresh medium containing butein at concentrations ranging between 0 and $20 \mu \mathrm{mol} / \mathrm{l}$ and incubated for $48 \mathrm{~h}$. The cell proliferation kit I (MTT) from Roche Applied Science (Mannheim, Germany) was used to measure cell viability. Briefly, $10 \mu 1$ labeling solution was added to each well of the 96-well plates. After $2 \mathrm{~h}$ in the $\mathrm{CO}_{2}$ incubator, $100 \mu \mathrm{l}$ solubilization solution was added to dissolve the purple crystals, which were the products of the MTT substrates. The absorbance was measured at $570 \mathrm{~nm}$ by a plate reader (Perkin-Elmer, Waltham, MA, USA). Absorbance measured in the MTT assays is expressed as a percentage of the control (defined as 100\%).

Cell cycle analysis. Cells were seeded in $25 \mathrm{~cm}^{2}$ flasks and incubated overnight to allow cells to adhere to the plate. A549 cells were treated with 10 and $20 \mu \mathrm{mol} / \mathrm{l}$ butein for $24 \mathrm{~h}$. Following treatment, control (untreated) and treated floating and adherent cells were collected by trypsinization. The cells $\left(1 \times 10^{6}\right.$ cells $\left./ \mathrm{ml}\right)$ were washed twice with cold phosphate-buffered saline (PBS) and fixed in 70\% ethanol. Immediately prior to the analysis, the cells were washed with PBS and stained with a solution containing propidium iodide (PI; $0.2 \mathrm{mg} / \mathrm{ml}$ ) for $1 \mathrm{~h}$ at $4^{\circ} \mathrm{C}$ and with RNase A $(0.1 \mathrm{mg} / \mathrm{ml})$ for $30 \mathrm{~min}$ at $37^{\circ} \mathrm{C}$. The distribution of cells in the cell cycle was measured by flow cytometry (Becton-Dickinson, Franklin Lakes, NJ, USA). Percentages of cells in the cell cycle phases were calculated using the Cell Quest software (Becton-Dickinson).

Measurement of apoptosis by ELISA. The induction of apoptosis by butein was assayed by the Nucleosome ELISA kit (Fitzgerald Industries International, Acton, MA, USA). This kit uses a photometric enzyme immunoassay to quantitatively determine the formation of cytoplasmic histone-associated DNA fragments (mono and oligonucleosomes) following apoptotic cell death. Apoptosis was determined by ELISA and

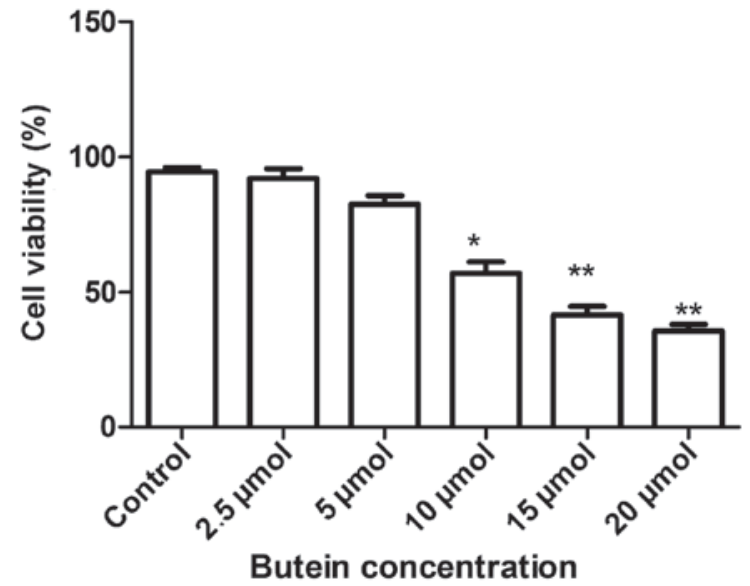

Figure 1. Effect of butein on the growth of A549 cells. A549 cells were treated with butein $(0-20 \mu \mathrm{mol} / \mathrm{l})$ for $48 \mathrm{~h}$. Viability was determined by the MTT assay. The data are presented as the percentages relative to the control (defined as $100 \%$ ). The data are expressed as the mean \pm standard deviation of triplicate samples from three independent experiments. ${ }^{*} \mathrm{P}<0.05$ and ${ }^{* *} \mathrm{P}<0.01$, vs. control.

the A549 cells $\left(1 \times 10^{5}\right)$ were treated with butein at 0,10 and $20 \mu \mathrm{mol} / \mathrm{l}$ for 12,24 and $48 \mathrm{~h}$ in a $96-$ well plate. The induction of apoptosis was evaluated by assessing the enrichment of nucleosome in the cytoplasm, and determined as described in the manufacturer's instructions for the nucleosome ELISA kit.

Quantitative polymerase chain reaction ( $q P C R)$ assay. Cells were seeded in 6-well plates for one day prior to treatment. The medium was removed and cells were cultured in fresh DMEM containing $20 \mu \mathrm{mol} / \mathrm{l}$ butein. Following $6 \mathrm{~h}$ treatment, total RNA was extracted from the cells using TRIzol reagent (Invitrogen Life Technologies, Carlsbad, CA, USA). The concentration and purity of RNA were determined by absorbance at 260/280 $\mathrm{nm}$. DNA strands were synthesized from $3 \mu \mathrm{g}$ total RNA by oligo-dT primers and M-MLV Reverse Transcriptase (Takara Bio, Inc., Shiga, Japan). Target fragments were quantified by real-time PCR, and an ABI prism 7700 Sequence Detection system (Applied Biosystems, Foster City, CA, USA) was employed for this assay. Taqman ${ }^{\circledR} / \mathrm{VIC}^{\circledR}$ MGB probes and primers for COX-2 [Assay ID (NM_000963.1): HS00153133_M1] and $\beta$-actin, and Real-time PCR Taqman Universal PCR Master mix were obtained from Applied Biosystems. PCR reactions were set up as described in the instructions, which was validated by the company. The signal obtained for $\beta$-actin was used as a reference housekeeping gene to normalize the quantity of total RNA amplified in each reaction. Relative gene expression data were analyzed using the $2^{-\Delta \Delta \mathrm{Ct}}$ method.

Western blot analysis. Cells were washed once with PBS (pH 7.4) and harvested into a $1.5 \mathrm{ml}$ microtube with $0.5 \mathrm{ml}$ lysis buffer (PBS, $1 \%$ NP-40, $0.5 \%$ sodium deoxycholate, $0.1 \%$ SDS). The lysis buffer contained protease inhibitors (40 mg/l PMSF, $0.5 \mathrm{mg} / \mathrm{l}$ aprotinin, $0.5 \mathrm{mg} / \mathrm{l}$ leupeptin, $1.1 \mathrm{mmol} / \mathrm{l}$ EDTA and $0.7 \mathrm{mg} / \mathrm{l}$ pepstatin). The harvested cells were then lysed with a cell disruptor (Branson Ultrasonics Corp., Danbury, CT, USA) on ice for $30 \mathrm{sec}$. The protein concentration of the cell lysate was determined by a Dc protein assay (Bio-Rad, Richmond, 
A

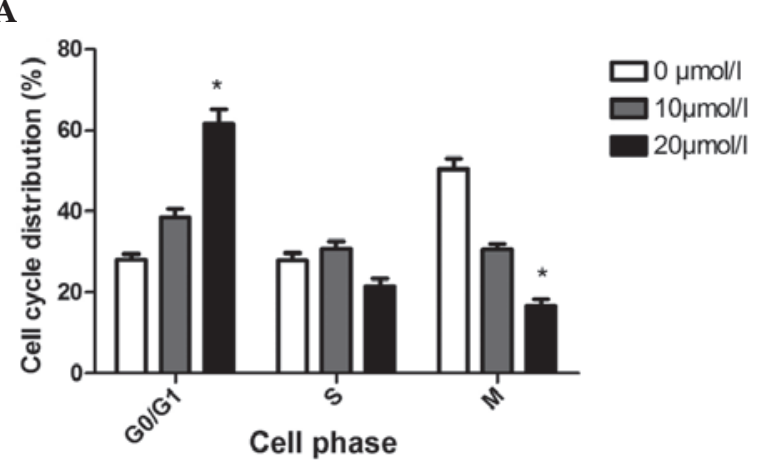

B

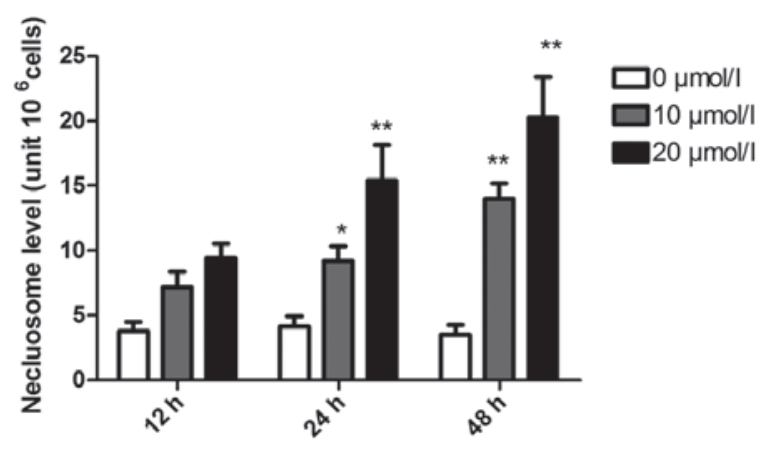

Figure 2. Butein-induced cell cycle arrest and apoptosis in A549 cells. (A) The effects of butein cell cycle distribution in A549 cells. A549 cells following treatment with 0,10 and $20 \mu \mathrm{mol} / 1$ of butein for $24 \mathrm{~h}$ were fixed and stained with PI and cell cycle distribution was analyzed by flow cytometry. (B) Induction of apoptosis in A549 cells by butein. A549 cells were cultured with 0,10 and $20 \mu \mathrm{mol} / 1$ of butein for 12,24 and 48 h. Cells were harvested and lysed with lysis buffer. Cell lysates containing cytoplasmic oligonucleosomes of apoptotic cells were analyzed by means of Nucleosome ELISA. Each value is the mean \pm standard deviation of three determinations. ${ }^{*} \mathrm{P}<0.05$ and ${ }^{* *} \mathrm{P}<0.01$, vs. control. PI, propidium iodide.

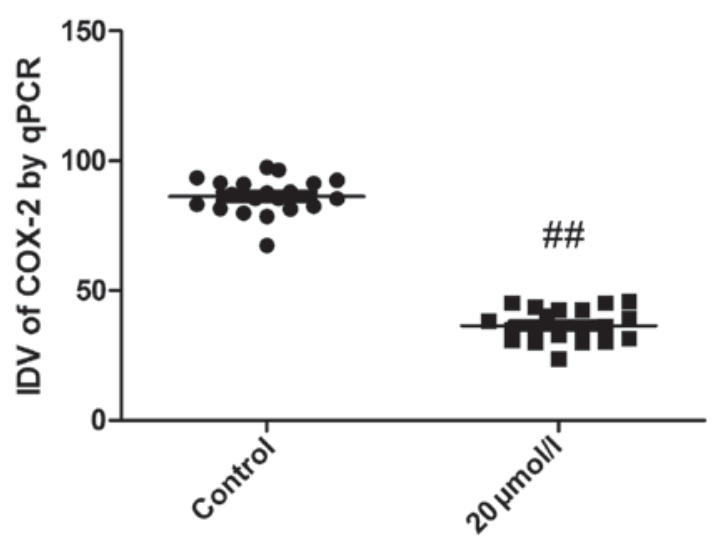

Figure 3. The mRNA expression of COX-2 in A549 cancer cells following butein treatment for $48 \mathrm{~h}$ by qPCR. ${ }^{\# \#} \mathrm{P}<0.01$, vs. control. COX-2, cyclooxygenase-2; qPCR, quantitative polymerase chain reaction.

CA, USA). Lysate protein $(50 \mu \mathrm{g})$ was separated on $10 \%$ SDS-PAGE and transferred onto an Immobilon polyvinylidene difluoride membrane (Millipore, Billerica, MA, USA). Anti-COX-2 (Cayman Chemicals, Ann Arbor, MI, USA), and secondary anti-mouse IgG antibodies conjugated with horseradish peroxidase (HRP; Santa Cruz Biotechnology, Inc.) were used for protein detection. An enhanced chemiluminescence detection kit (Amersham Pharmacia Biotech, Piscataway, NJ, USA) provided the chemiluminescence substrate for HRP, and the targeted protein was visualized by autoradiography (Xue Wang, The First Hospital of Jilin University, Changchun, China).

Statistical analysis. Values are expressed as the mean \pm standard deviation. The data were analyzed by one-way analysis of variance. $\mathrm{P}<0.05$ was considered to indicate a statistically significant difference.

\section{Results}

Butein inhibits the growth of human lung cancer cells. To evaluate the antiproliferative activities of butein on A549 cells, the MTT assay was applied. As shown in Fig. 1, exposure of A549 cells to increasing concentrations of butein (0-20 $\mu \mathrm{mol} / \mathrm{l})$
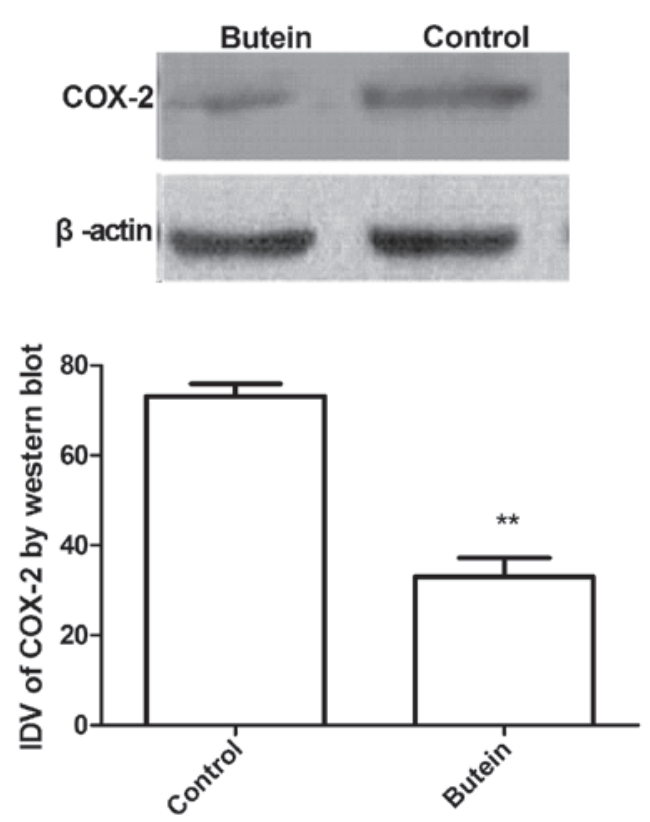

Figure 4. The protein expression of COX-2 in A549 cancer cells following butein treatment for $48 \mathrm{~h}$ by western blotting. ${ }^{* *} \mathrm{P}<0.01$, vs. control. COX-2, cyclooxygenase-2

for $72 \mathrm{~h}$ resulted in a dose-dependent growth inhibition. The lower butein concentrations $(2.5-5 \mu \mathrm{mol} / \mathrm{l})$ did not affect A549 cell viability significantly, whereas concentrations between 10 and $20 \mu \mathrm{mol} / 1$ significantly reduced cell viability. The $\mathrm{IC}_{50}$ for the $48 \mathrm{~h}$ incubation time was $\sim 14.18 \mu \mathrm{M}$. Therefore, 15-20 $\mu \mathrm{mol} / 1$ doses were selected for further butein treatment studies.

Butein-induced cell cycle arrest and apoptosis in A549 cells. The results on the effect of butein on cell cycle progression of A549 are shown in Fig. 2A. As compared with the control, $10 \mu \mathrm{mol} / \mathrm{l}$ butein increased the population of $\mathrm{G} 1$ phase from 35.3 to $42.4 \%$. This effect was enhanced when A549 cells were treated with $20 \mu \mathrm{mol} / \mathrm{l}$ butein $(61.5 \%$ cell population in G1 phase).

Fig. 2B shows the time course of DNA fragmentation in continuous treatment with 10 and $20 \mu \mathrm{mol} / 1$ butein. DNA 
fragmentation of A549 was found at $12 \mathrm{~h}$ and maximized at $48 \mathrm{~h}$ following the addition of butein. In contrast to the control, when cells were treated with butein, the number of cells undergoing apoptosis increased between $~ 3.3$ and 8.2-fold at 10 and $20 \mu \mathrm{mol} / \mathrm{l}$ butein, respectively, at $48 \mathrm{~h}$.

mRNA expression of COX-2 following butein treatment. qPCR was performed to detect the mRNA expression of COX-2 in A549 cancer cells following butein treatment. As shown in Fig. 3, mRNA levels of COX-2 was significantly reduced following butein treatment as compared with the control group $(\mathrm{P}<0.05)$, which showed that mRNA expression of COX-2 was downregulated by butein treatment in A549 cancer cells.

Protein expression of COX-2 in A549 cells following butein treatment. A549 cells were treated with $20 \mu \mathrm{mol} / 1$ butein, and cultured for $24 \mathrm{~h}$. Protein lysates were prepared for western blot analysis. As shown in Fig. 4, protein levels of COX-2 were significantly reduced in A549 cells following butein treatment compared with the control $(\mathrm{P}<0.05)$, which was in agreement with the result that butein treatment may downregulate COX-2 mRNA expression in A549 cancer cells.

\section{Discussion}

Lung cancer is the leading cause of cancer-related mortality worldwide. NSCLC accounts for $\sim 75-85 \%$ of lung cancer. NSCLCs commonly develop resistance to radiation and chemotherapy, and often present at stages beyond surgical respectability. Since current treatment modalities are inadequate, novel therapies are required to reduce the effects of the increasing incidence in pulmonary neoplasm $(14,15)$. Butein is a polyphenolic compound, which may be extracted from the stem bark of cashews and Rhus verniciflua Stokes, and used as a food additive and a traditional herbal medicine. Previous studies suggested that butein exhibits anticancer activity and that butein may induce apoptosis in human promyelocytic leukemia (16) and B16 melanoma cells (17). In vitro, butein may suppress the proliferation of the majority of human cancers, including breast and colon carcinomas, osteosarcoma, prostate tumor and hepatic stellate cells $(3,9,18-21)$. The present study indicated that butein inhibits cell proliferation of lung cancer in a dose-dependent manner, which is in agreement with previous studies $(3,18-21)$.

COX-2 is inducible by inflammatory stimuli, including cytokines, growth factors, and tumor promoters, and is upregulated in a variety of malignancies and favors the growth of malignant cells by stimulating proliferation and angiogenesis $(22,23)$. In previous years, a large number of studies demonstrated that COX-2 is overexpressed in ovarian cancer (24-26). Furthermore, Arico et al (27) found that COX-2 is capable of inducing angiogenesis via the vascular endothelial growth factor and prostaglandin production and may also inhibit apoptosis by inducing the antiapoptotic factor Bcl-2, as well as activating antiapoptotic signaling through Akt/protein kinase B. These results suggest that COX-2 is important in the generation and progression of solid tumors, and that inhibition of COX-2 may inhibit the growth of a variety of solid malignancies. In the present study, butein mediated the downregulation of COX2 expression in human lung cancer cells and induced cancer cell apoptosis, which may be a key molecular mechanism of butein in anticancer therapy.

In conclusion, butein was observed to decrease COX-2 expression in cancerous lung cells in the current study. Considering the importance of COX-2 in lung carcinogenesis, the findings may provide the scientific basis for potential pharmaceutical application of butein.

\section{Acknowledgements}

This study was supported by grants from the National Natural Science Foundation of Jilin (Project no. 83657488).

\section{References}

1. Szuster-Ciesielska A, Plewka K and Kandefer-Szerszeń M: Betulin, betulinic acid and butein are inhibitors of acetaldehyde-induced activation of liver stellate cells. Pharmacol Rep 63: 1109-1123, 2011.

2. Martineau L: Large enhancement of skeletal muscle cell glucose uptake and suppression of hepatocyte glucose-6-phosphatase activity by weak uncouplers of oxidative phosphorylation. Biochim Biophys Acta 1820: 133-150, 2012.

3. Khan N, Adhami VM, Afaq F and Mukhtar H: Butein induces apoptosis and inhibits prostate tumor growth in vitro and in vivo. Antioxid Redox Signal 16: 1195-1204, 2012.

4. Son YO, Lee KY, Lee JC, Jang HS, Kim JG, Jeon YM and Jang YS: Selective antiproliferative and apoptotic effects of flavonoids purified from Rhus verniciflua Stokes on normal versus transformed hepatic cell lines. Toxicol Lett 155: 115-125, 2005.

5. Moon DO, Kim MO, Choi YH, Hyun JW, Chang WY and Kim GY: Butein induces G(2)/M phase arrest and apoptosis in human hepatoma cancer cells through ROS generation. Cancer Lett 288: 204-213, 2010.

6. Pandey MK, Sung B, Ahn KS and Aggarwal BB: Butein suppresses constitutive and inducible signal transducer and activator of transcription (STAT) 3 activation and STAT3-regulated gene products through the induction of a protein tyrosine phosphatase SHP-1. Mol Pharmacol 75: 525-533, 2009.

7. Moon DO, Kim MO, Lee JD, Choi YH and Kim GY: Butein suppresses c-Myc dependent transcription and Akt-dependent phosphorylation of hTERT in human leukemia cells. Cancer Lett 286: 172-179, 2009.

8. Kim N: Butein sensitizes human leukemia cells to apoptosis induced by tumor necrosis factor-related apoptosis inducing ligand (TRAIL). Arch Pharm Res 31: 1179-1186, 2008.

9. Samoszuk M, Tan J and Chorn G: The chalcone butein from Rhus verniciflua Stokes inhibits clonogenic growth of human breast cancer cells co-cultured with fibroblasts. BMC Complement Altern Med 5: 5, 2005.

10. Prosperi JR, Mallery SR, Kigerl KA, Erfurt AA and Robertson FM: Invasive and angiogenic phenotype of MCF-7 human breast tumor cells expressing human cyclooxygenase-2. Prostaglandins Other Lipid Mediat 73: 249-264, 2004.

11. Takahashi Y, Kawahara F, Noguchi M, Miwa K, Sato H, Seiki M, Inoue $\mathrm{H}$, Tanabe $\mathrm{T}$ and Yoshimoto $\mathrm{T}$ : Activation of matrix metalloproteinase-2 in human breast cancer cells overexpressing cyclooxygenase-1 or -2. FEBS Lett 460: 145-148, 1999.

12. Trifan OC and Hla T: Cyclooxygenase- 2 modulates cellular growth and promotes tumorigenesis. J Cell Mol Med 7: 207-222, 2003.

13. Nakatsugi S, Ohta T, Kawamori T, Mutoh M, Tanigawa T, Watanabe K, Sugie S, Sugimura T and Wakabayashi K: Chemoprevention by nimesulide, a selective cyclooxygenase-2 inhibitor, of 2-amino-1-methyl-6-phenylimidazo[4,5-b]pyridine (PhIP)-induced mammary gland carcinogenesis in rats. Jpn J Cancer Res 91: 886-892, 2000.

14. Kim PK, Park SY, Koty PP, Hua Y, Luketich JD and Billiar TR: Fas-associating death domain protein overexpression induces apoptosis in lung cancer cells. J Thorac Cardiovasc Surg 125: 1336-1342, 2003.

15. Cheng YL, Chang WL, Lee SC, Liu YG, Lin HC, Chen CJ, Yen CY, Yu DS, Lin SZ and Harn HJ: Acetone extract of Bupleurum scorzonerifolium inhibits proliferation of A549 human lung cancer cells via inducing apoptosis and suppressing telomerase activity. Life Sci 73: 2383-2394, 2003. 
16. Kim NY, Pae HO, Oh GS, Kang TH, Kim YC, Rhew HY and Chung HT: Butein, a plant polyphenol, induces apoptosis concomitant with increased caspase-3 activity, decreased Bcl-2 expression and increased Bax expression in HL-60 cells. Pharmacol Toxicol 88: 261-266, 2001.

17. Iwashita K, Kobori M, Yamaki K and Tsushida T: Flavonoids inhibit cell growth and induce apoptosis in B16 melanoma 4A5 cells. Biosci Biotechnol Biochem 64: 1813-1820, 2000.

18. Wang Y, Chan FL, Chen S and Leung LK: The plant polyphenol butein inhibits testosterone-induced proliferation in breast cancer cells expressing aromatase. Life Sci 77: 39-51, 2005.

19. Yit CC and Das NP: Cytotoxic effect of butein on human colon adenocarcinoma cell proliferation. Cancer Lett 82: 65-72, 1994.

20. Jang HS, Kook SH, Son YO, Kim JG, Jeon YM, Jang YS, Choi KC, Kim J, Han SK, Lee KY, et al: Flavonoids purified from Rhus verniciflua Stokes actively inhibit cell growth and induce apoptosis in human osteosarcoma cells. Biochim Biophys Acta 1726: 309-316, 2005.

21. LeeSH,SeoGS,KimHandSohnDH:2',4',6'-Tris(methoxy-methoxy) chalcone attenuates hepatic stellate cell proliferation by a heme oxygenase-dependent pathway. Biochem Pharmacol 72: 1322-1333, 2006.
22. Dempke W, Rie C, Grothey A and Schmoll HJ: Cyclooxygenase-2: a novel target for cancer chemotherapy? J Cancer Res Clin Oncol 127: 411-417, 2001.

23. Williams CS, Mann M and DuBois RN: The role of cyclooxygenases in inflammation, cancer, and development. Oncogene 18: 7908-7916, 1999.

24. Denkert C, Köbel M, Pest S, Koch I, Berger S, Schwabe M, Siegert A, Reles A, Klosterhalfen B and Hauptmann S: Expression of cyclooxygenase-2 is an independent prognostic factor in human ovarian carcinoma. Am J Pathol 160: 893-903, 2002.

25. Erkinheimo TL, Lassus H, Finne P, van Rees BP, Leminen A, Ylikorkala O, Haglund C, Butzow R and Ristimäki A: Elevated cyclooxygenase-2 expression is associated with altered expression of $\mathrm{p} 53$ and SMAD4, amplification of HER-2/neu, and poor outcome in serous ovarian carcinoma. Clin Cancer Res 10: 538-545, 2003.

26. Li S, Miner K, Fannin R, Carl Barrett J and Davis BJ: Cyclooxygenase- 1 and 2 in normal and malignant human ovarian epithelium. Gynecol Oncol 92: 622-627, 2004.

27. Arico S, Pattingre S, Bauvy C, Gane P, Barbat A, Codogno P and Ogier-Denis E: Celecoxib induces apoptosis by inhibiting 3-phosphoinositide-dependent protein kinase-1 activity in the human colon cancer HT-29 cell line. J Biol Chem 277: 27613-27621, 2002. 